\title{
Response of the equatorial electrojet to solar flare related X-ray flux enhancements
}

\author{
G. Manju and K. S. Viswanathan \\ Space Physics Laboratory, Vikram Sarabhai Space Centre, Trivandrum-695 022, Kerala, India
}

(Received June 14, 2004; Revised January 31, 2005; Accepted February 1, 2005)

\begin{abstract}
The response of ionospheric E-region electric fields and currents to solar flare related X-ray flux enhancements are studied at the magnetic equatorial location of Trivandrum $\left(8.5^{\circ} \mathrm{N}, 77^{\circ} \mathrm{E}\right.$; dip $\left.0.5^{\circ} \mathrm{N}\right) \mathrm{using} \mathrm{VHF}(54.95 \mathrm{MHz})$ coherent backscatter radar observations in the altitude region of 95-110 km conducted during daytime. The amplitude of the Solar Flare Effects (SFE) observed in the earth's magnetic field variations at Trivandrum have been examined in relation to that at Alibag and it is found that the ratio of the SFE amplitudes at the two stations lies in the range of 1.8-2.6. The backscattered power of the VHF radar showed a substantial reduction during the peak phase of all the strong X-rank flares studied. It has also been observed that there is a sharp fall in the ratio of the field line integrated Hall conductivity $\left(\sigma_{2}\right)$ to the field line integrated Pedersen conductivity $\left(\sigma_{1}\right)$ in the dynamo region $\left(\int \sigma_{2} d s / \int \sigma_{1} d s\right)$ during strong flare times in relation to normal times. The time variations of mean Doppler frequency $\left(\overline{f_{D}}\right)$ of the backscattered signals have been observed to indicate a fall close to the peak phase of the strong flare events. Another new result is the radar observed presence of westward electric field for a long duration of 2-3 hours during a partial counter electrojet (CEJ) event that occurred on one of the days (8 July 1992) studied. The implications of the observations are discussed in detail.
\end{abstract}

Key words: Equatorial electrojet, solar flare effect, magnetic crochet, radar, conductivity.

\section{Introduction}

Solar flare effect is essentially the disturbance in the geomagnetic field elements, induced by a solar flare. Solar flares are comprised of X-ray flares. An X-ray flare is an enhancement in the X-ray solar flux intensity at wavelengths less than $20 \AA$. The X-ray flux enhancements, during solar flare events, are classified based on their strengths in terms of the peak burst intensity $\left(I_{B}\right)$ measured by satellites in the wavelength band of 1-8 $\AA$ and it is expressed in units of $\mathrm{Wm}^{-2}$. X rank flares are the strongest $\left(I_{B}>10^{-4} \mathrm{Wm}^{-2}\right)$ and $\mathrm{B}$ rank flares are the weakest $\left(I_{B}<10^{-6} \mathrm{Wm}^{-2}\right)$ according to this classification. Brightness is the relative maximum brightness of a flare in $\mathrm{H} \alpha$. A flare is classified as faint $(\mathrm{F})$, normal $(\mathrm{N})$ or brilliant $(\mathrm{B})$ depending on the brightness. X-ray flares are observed in the light of the $\mathrm{H} \alpha$ flares which often accompany solar flares.

The enhancement of the horizontal component $(\mathrm{H})$ of the geomagnetic field due to an X-ray flare event is called a Solar Flare effect (SFE). The onset, peak and end phases of a flare are characterized respectively by the time when a sudden increase in X-ray peak burst intensity $\left(I_{B}\right)$ occurs, the time when $I_{B}$ attains a maximum value and the time when the flux has decayed to half the peak value. The solar flare effects appear to be an augmentation of the ionospheric current system existing at the time of the flare which is manifested as a corresponding change $\mathrm{SFE}(\mathrm{H})$ in the horizontal component $(\mathrm{H})$ of the earth's magnetic field. The maximum

Copy right (C) The Society of Geomagnetism and Earth, Planetary and Space Sciences (SGEPSS); The Seismological Society of Japan; The Volcanological Society of Japan; The Geodetic Society of Japan; The Japanese Society for Planetary Sciences; TERRAPUB. enhancement in $\mathrm{H}$ value over the pre-flare level indicates the magnitude [SFE $(\mathrm{H})]$ of an SFE event. The solar flare (magnetic crochet) related current was regarded as an augmentation of the $S_{q}$ current system (Chapman, 1961) in the past. Later studies brought out significant differences between $S_{q}$ and crochet current systems (Yasuhara and Maeda, 1961; Van Sabben, 1968). Oshio et al. (1967) studied the solar flare effect on the geomagnetic field on a global basis and suggested that the seat of the ionospheric current is a little lower than the layer for the $S_{q}$ current system. The response of the ionosphere to solar flares in terms of the increase in electron density $(\mathrm{Ne})$, Pedersen $\left(\sigma_{1}\right)$ and Hall $\left(\sigma_{2}\right)$ conductivities and Total Electron Content (TEC) in the dynamo region have been discussed by Sato (1975). Solar flare effects on zonal and meridional currents at the equatorial electrojet station of Annamalai Nagar has been presented by Rastogi (1996). Rastogi et al. (1997) have studied the changes in the three components $(\mathrm{H}, \mathrm{D}$ and $\mathrm{Z}$ or $\mathrm{X}, \mathrm{Y}$ and $\mathrm{Z}$, as the case may be) of the geomagnetic field for a chain of ten geomagnetic observatories in India, during an intense solar flare on 15 June 1991 and the subsequent sudden commencement. They found that SFE $(\mathrm{H})$ values were positive at all stations and decreased progressively with latitude. SFE (Y) values were negative at all stations and $\operatorname{SFE}(Z)$ values were positive at equatorial and negative at non-electrojet stations. They have explained the observed irregular variations of $\mathrm{Z}$ components at different stations in terms of possible distortions in the altitude profile of the ionospheric currents at low latitudes.

In the present study, the temporal variations of the backscattered power and the mean Doppler frequency, dur- 
Table 1.

\begin{tabular}{ccccccc}
\hline Date & Ap & Rank & Optical & & Duration & \\
& & & & Onset time (IST) & Peak time (IST) & End time (IST) \\
\hline Dec. 24, 1991 & 10 & $\times 1.4$ & 2B & 1543 & 1600 & 1703 \\
Mar. 25, 1991 & 131 & $\times 1.5$ & 1B & 1331 & 1341 & 1409 \\
Mar. 29, 1991 & 4 & $\times 2.4$ & 2B & 1212 & 1218 & 1304 \\
Jul. 08, 1992 & 5 & $\times 1.2$ & 1B & 1512 & 1520 & 1556 \\
\hline
\end{tabular}

(a)

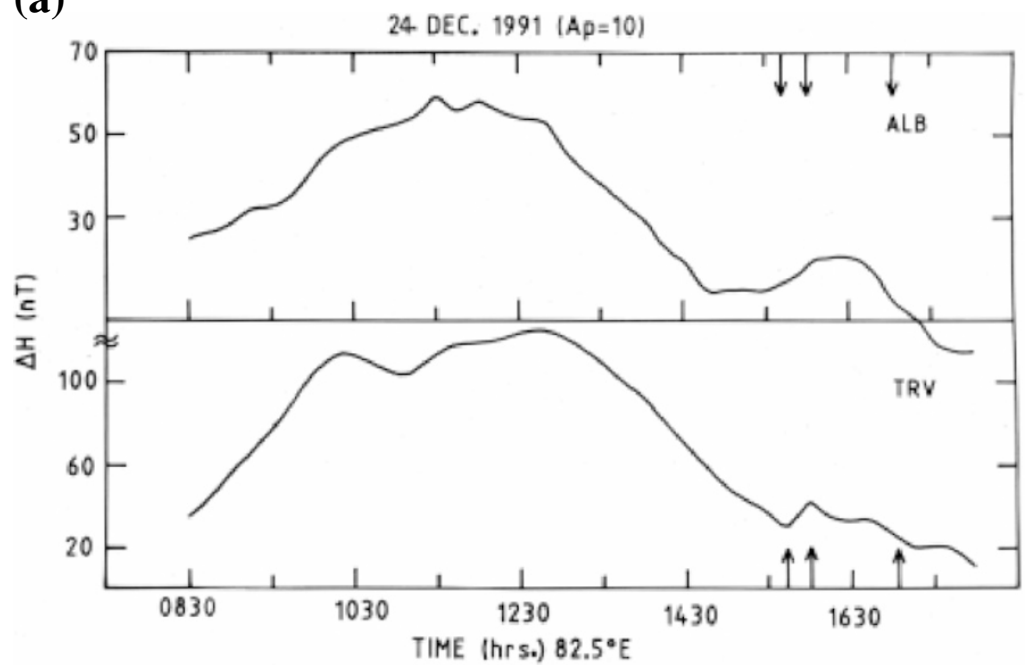

(b)

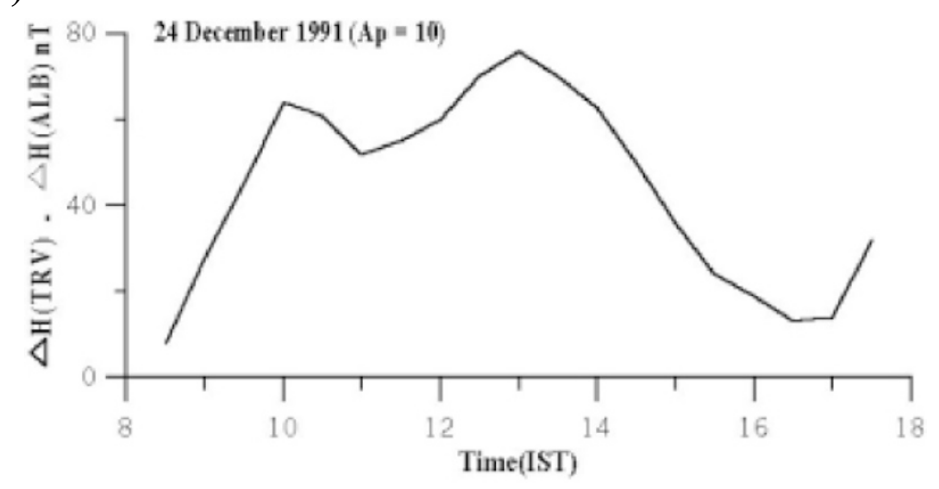

Fig. 1. (a) Daytime variations of $\Delta \mathrm{H}$ on 24 December 1991 at TRV and ALB (an off equatorial station). (b) Daytime variations of $(\Delta \mathrm{H})_{\mathrm{TRV}}-(\Delta \mathrm{H})_{\mathrm{ALB}}$ on 24 December 1991

ing strong flare events, have been presented for the first time. The other new result is the radar observed presence of a westward electric field for a long duration of 2-3 hours during a CEJ event with a transient SFE event riding over it. Previously, westward electric fields during CEJ events have been observed for short durations only. The flare time profile of $\int \sigma_{2} d s / \int \sigma_{1} d s$ is compared with that obtained for normal times.

\section{Experimental Set Up}

The present study has been carried out using data from VHF backscatter radar observations at the magnetic equatorial location of Trivandrum $\left(0.5^{\circ} \mathrm{N}\right)$. Detailed specifications, data recording and analysis procedure for VHF backscatter radar (operating at $54.95 \mathrm{MHz}$ and thus re- sponding to $2.7 \mathrm{~m}$ scale size ionisation irregularities) have been described in Reddy et al. (1987). The parameters estimated from the radar Doppler spectra are the power (zeroth moment), mean Doppler frequency $\overline{f_{D}}$, (first moment) and the width of the spectrum (second moment). The power is a measure of the strength of the scattering ionisation irregularities present in the volume illuminated by the radar, mean Doppler frequency gives the mean drift velocity of the irregularities (and thereby provide a measure of the E-region electric field) and the width of the spectrum is a gross indicator of the strength of plasma turbulence. For the Trivandrum radar geometry, negative (positive) Doppler shift corresponds to westward (eastward) drift of irregularities in the presence of an eastward (westward) electric field, $E_{y}$ which is of global scale dynamo origin. 


\section{Studies on X-ray Flare Events}

The response of the E region electric fields and currents to various X-ray flare events of different ranks have been investigated using VHF radar observations at Trivandrum. For the study, $\Delta \mathrm{H}$ values (deviations in $\mathrm{H}$ with respect to the night time levels) at Trivandrum and off electrojet latitudes (Alibag) are used in association with the radar observations. The results of the study carried out for three X-ray flare events of rank $\mathrm{X}$ are presented. The relevant information regarding the events studied is given in Table 1 . Two of the flare events are on magnetically quiet days, while the third event (25 March 1991) is on a highly disturbed day. For 24 December 1991, the Doppler values are not available but information on the strength of the backscattered signal is available as has been recorded on a pen chart recorder. The magnetic field variations obtained on 29 March 1991, which is a quiet day (without any disturbance effects or phenomena like CEJ) is also examined to show the pure solar flare effects on the geomagnetic field.

\section{Radar Observations of Ionisation Irregularities in Association with Magnetic Field Variations for Strong Flare Events}

The response of electric fields to three X-rank flare events is examined using the VHF radar measured irregularity strength and/or the Doppler values.

\subsection{December 1991 event}

The details of this flare event, which occurred on a magnetically quiet day, are given in Table 1 . The flare begins at $1543 \mathrm{hr}$ and ends at $1703 \mathrm{hr}$. The daytime variations of $\Delta \mathrm{H}$ at Trivandrum (TRV) and Alibag (ALB) are shown on the bottom and top panels respectively in Fig. 1(a). The arrows shown in the figure indicate the onset, peak and end phases of the flare (in terms of the peak burst intensity). The $\Delta H$ values at TRV start increasing from morning hours, attain a maximum of about $125 \mathrm{nT}$ around $1245 \mathrm{hr}$ and then decrease. Beyond $1543 \mathrm{hr}$ which is the onset and development phase of the flare, $\Delta \mathrm{H}$ values show an increase and attain maximum value around $1600 \mathrm{hr}$, as a significant augmentation (of $\Delta \mathrm{H}$ ) superposed over the general decay pattern of $\Delta \mathrm{H}$, which is observed at both Trivandrum and Alibag. The rise in SFE $(\mathrm{H})$ upto the peak is steep and rapid where as beyond the flare peak phase the decay in SFE $(\mathrm{H})$ amplitude is more gradual. The amplitude of SFE (H) at TRV is low $(\sim 12 \mathrm{nT})$ as the flare occurred in the afternoon hours when $\Delta H$ values are also less due to reduced conductivities. The SFE (H) amplitude at ALB is $\sim 7 \mathrm{nT}$ at $1606 \mathrm{hr}$. The value remains at that level until $1636 \mathrm{hr}$ and then decreases. The decrease is gradual compared to the rise in this case also. Beyond $1703 \mathrm{hr}$ the $\Delta \mathrm{H}$ values fall off at both locations and attain the levels that would have existed had there been no flare mainly due to the fast decreasing conductivities during these times. The magnetic field values for ALB remain high around the peak phase for a longer duration compared to TRV. Figure 1(b) shows the time variations of $(\Delta \mathrm{H})_{\mathrm{TRV}}-(\Delta \mathrm{H})_{\mathrm{ALB}}$, which represents the strength of the electrojet at different times. The figure shows that a partial CEJ is in progress in the afternoon ( 1530-1730 hr) as evidenced by the depression during this period. The flare occurred when the CEJ was already in progress. This CEJ

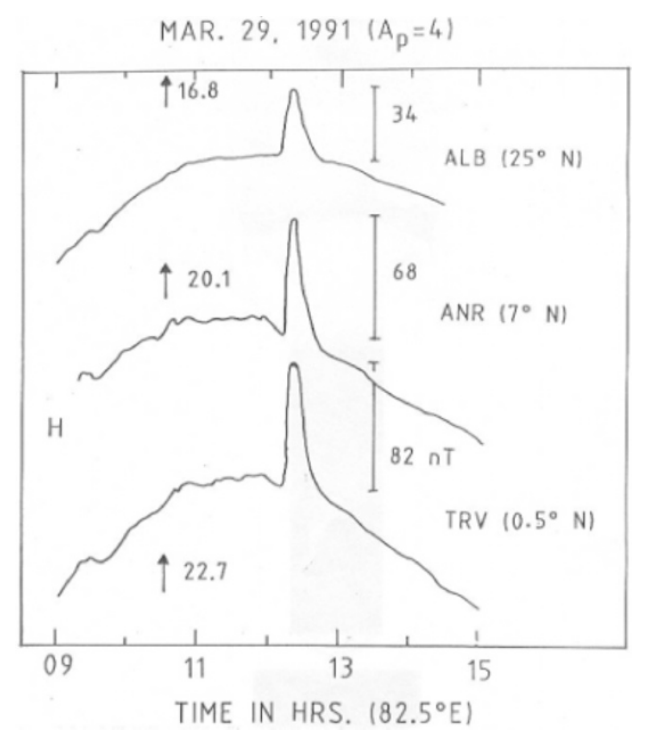

Fig. 2. Daytime variations of $\mathrm{H}$ for three stations on 29 March 1991.

event is the cause for magnetic field values at ALB remaining seemingly high for a longer duration around the peak phase of the flare compared to TRV. That is the CEJ effect attains its peak after the flare peak phase and the reducing effect on $\Delta \mathrm{H}$ also increases at TRV after the flare peak phase. The $\Delta H$ variations on 29 March 1991, a magnetically quiet day (without CEJ effects) for three stations, prior to, during and after a strong flare are shown in Fig. 2 for comparison. The details of the flare are given in Table 1 . It is seen from the figure that the $\mathrm{H}$ field shows sudden sharp increase close to $1213 \mathrm{hr}$, attains a maximum at 1221 $\mathrm{hr}$ and decreases to pre-flare level, close to the end phase of the flare at $1304 \mathrm{hr}$. There is a time delay between the phases of the flare and their ionospheric effects due to the finite response time of the ionosphere (Donelly, 1968). The SFE (H) amplitudes at Trivandrum (TRV), Annamalainagar (ANR) and Alibag (ALB) are shown as 82, 68 and 34 nT respectively. This shows that $\mathrm{SFE}(\mathrm{H})$ decreases from TRV to low latitudes in the absence of CEJ effects. The ratio of SFE $(\mathrm{H})$ at TRV to ALB is 2.4.

Due to non-availability of Doppler spectral data, for this event, the signal strength of the radar returns as recorded on a pen chart recorder has been used. The chart recorder speed is $10 \mathrm{~cm} / \mathrm{hr}$ and is adjustable. It has a range of $10 \mathrm{~V}$. The time variation of the radar echo signal for the daytime is shown in the Fig. 3. The onset, peak and end phases of the flare are indicated by arrows in the figure. The signal strength increases from morning and attains a maximum value of $6.6 \mathrm{~V}$ at $1245 \mathrm{hr}$. It then decreases gradually till $1543 \mathrm{hr}$, which is the onset phase of the flare. The radar signal returns start decreasing quiet rapidly beyond 1543 hr. It decreases from a value of $2.6 \mathrm{~V}$ at $\sim 1543 \mathrm{hr}$ to 1.2 $\mathrm{V}$ by $1600 \mathrm{hr}$, which is the peak phase of the flare and further to a low value of $0.9 \mathrm{~V}$ by $1621 \mathrm{hr}$. Then it is fairly constant till $1633 \mathrm{hr}$. Later it again increases close to the end phase of the flare to reach a value of $1.8 \mathrm{~V}$ at $1709 \mathrm{hr}$ before decreasing to low values, close to the time of evening reversal of the EEJ. The figure clearly shows the sharp fall in the radar signal power close to the peak phase of the $\mathrm{X}$ 


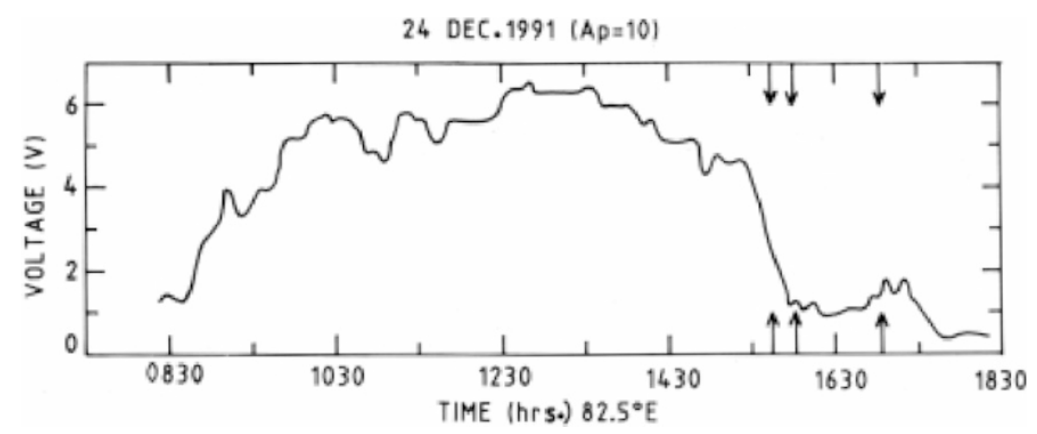

Fig. 3. Daytime variations of VHF radar signal strength (voltage) on 24 December 1991.

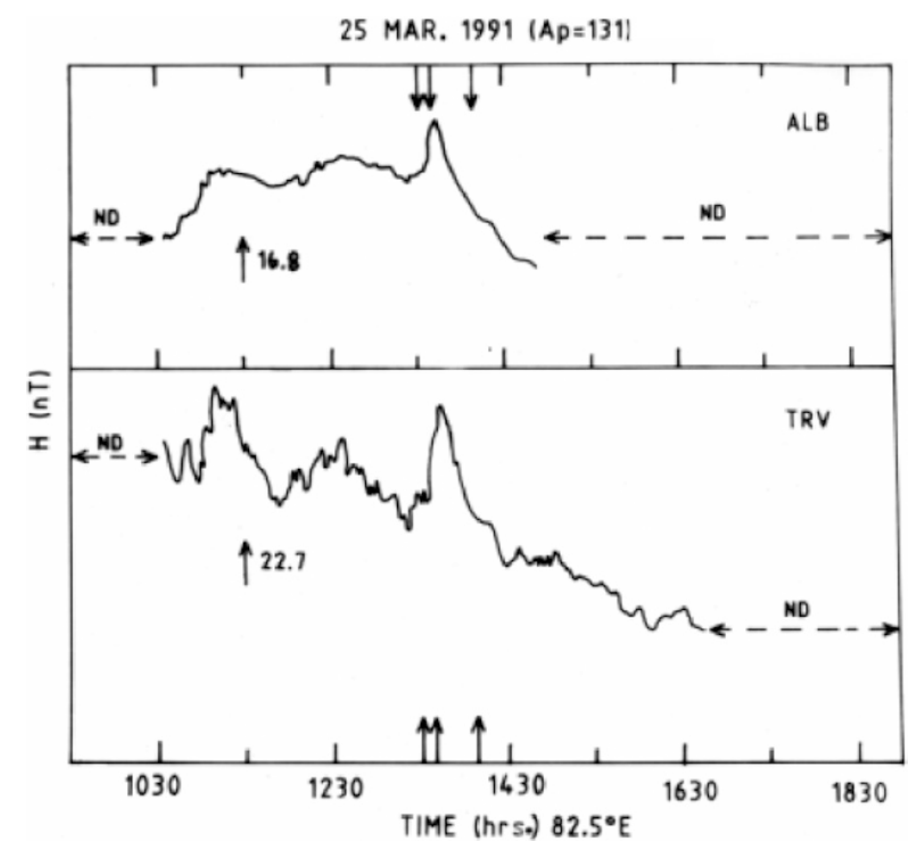

Fig. 4. Daytime variation of H for TRV and ALB for the disturbed day of 25 March 1991. The scale for each station is indicated in figure.

rank flare.

\subsection{March 1991 event}

This is a magnetically disturbed day, as indicated by the high Ap value of 131. Disturbance effects are seen on this day both in the magnetic field variations and the radar observed Doppler and signal strength. The clear signatures seen in the magnetograms and the VHF radar observations indicate that flare effects are dominant in relation to disturbance effects during the time of the solar flare event.

The flare event begins at $1331 \mathrm{hr}$, attains a peak at 1341 $\mathrm{hr}$ and ends at $1409 \mathrm{hr}$. The temporal variations in $\mathrm{H}$, for TRV and ALB are shown in the bottom and top panels respectively of Fig. 4. The scale values for both the stations are shown in figure. ND indicates no data. Disturbance related fluctuations in $\mathrm{H}$ can be clearly seen at both stations in the figure. Nevertheless, the SFE (H) amplitude is clearly identifiable for both the stations from the figure. The SFE (H) amplitude at TRV is $50 \mathrm{nT}$ while that at ALB is 21 nT. This flare occurs at $1330 \mathrm{hr}$ during which time the ionospheric conductivity is quiet high, leading to the large SFE (H) amplitudes at the two stations. For this event the ratio of SFE $(\mathrm{H})$ at TRV to that at ALB is 2.4.

The time variations of the signal strength (shown as rel- ative power, which is the power normalized with respect to the peak power at that time) backscattered from the irregularities, for the altitudes of 99, 101, 104 and $107 \mathrm{~km}$ are shown in Fig. 5 during 0950-1600 hr. The arrows shown correspond to the onset, peak and end phases of the flare. Similar arrows are used to indicate these three phases in the subsequent figures also. The power values show significant fluctuations at different altitude levels in the EEJ, in time scales of $0.5-1.0 \mathrm{hr}$ throughout the daytime with increase and decrease associated with magnetically disturbed conditions (Viswanathan, 1986). Nevertheless, a significant reduction in backscattered power occurs around $1345 \mathrm{hr}$ coinciding with the peak phase of the flare (as can be clearly seen in the figure, corresponding to the altitudes of 99, 101 and $104 \mathrm{~km}$ ). The power decreases by more than $90 \%$ with respect to the pre flare level. For the altitude of $107 \mathrm{~km}$, very weak signal only is observed right from $1340 \mathrm{hr}$ onwards perhaps due to the presence of weak electron density gradients $(\nabla N)$ and hence flare related changes could not be identified. A fall in backscattered power is also seen close to $1430 \mathrm{hr}$ after the flare end phase, at the altitudes of 99,101 and $104 \mathrm{~km}$ (during which time the $\mathrm{H}$ variations indicate a decrease Fig. 4). The fact that the reduction in signal around 


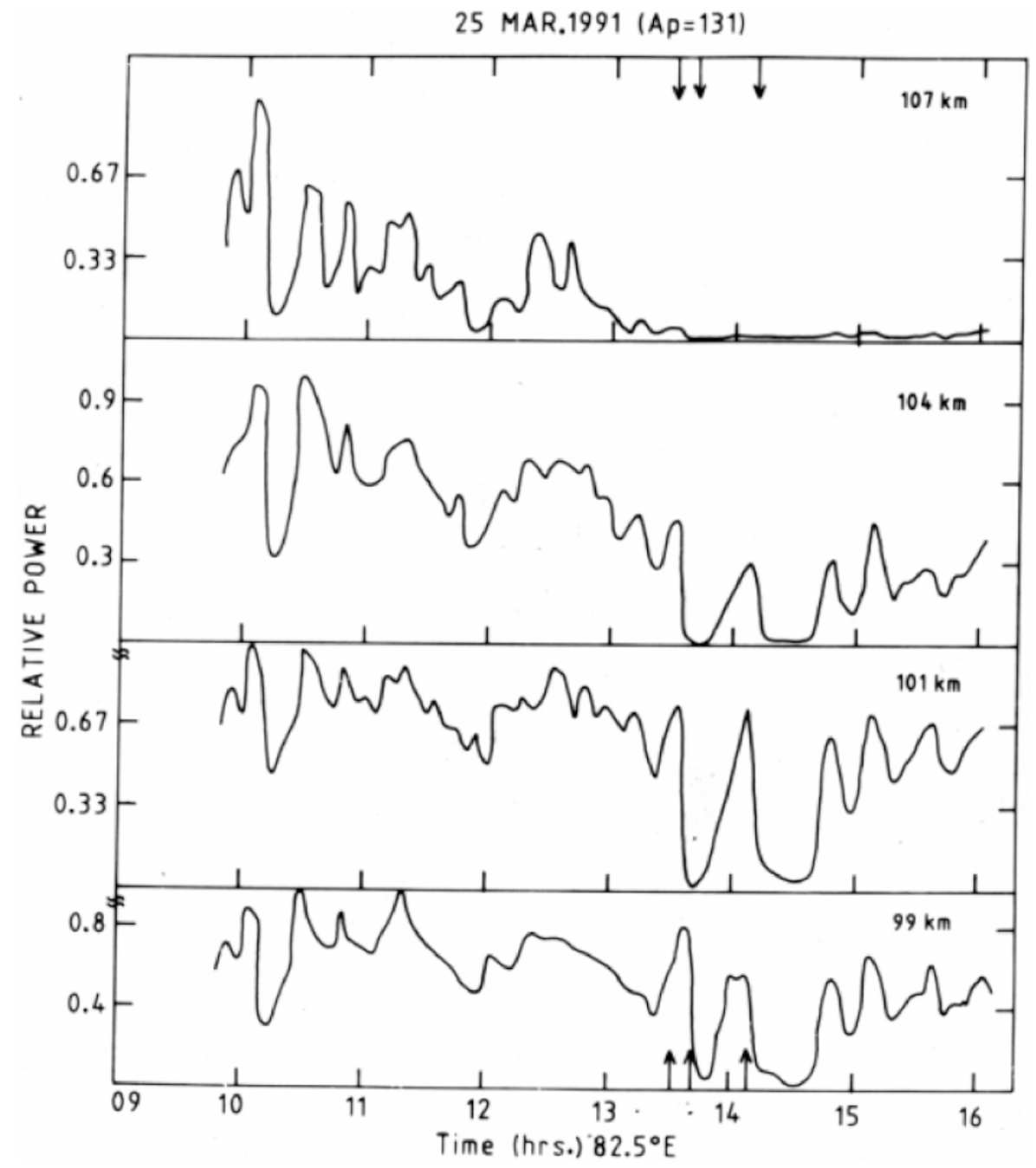

Fig. 5. Time variation of VHF backscattered power from $2.7 \mathrm{~m}$ scale irregularities in the altitude range of 99-107 km on $25 \mathrm{March} 1991$.

$1345 \mathrm{hr}$ is a manifestation of flare effects while that around $1430 \mathrm{hr}$ is possibly due to disturbance effects is brought out by the different $\mathrm{H}$ variations and ionograms corresponding to those times. Figure 6 shows the ionograms corresponding to $1330 \mathrm{hr}$ (before flare onset), $1345 \mathrm{hr}$ (close to flare peak phase), $1400 \mathrm{hr}$ (close to end phase) and $1430 \mathrm{hr}$ (after flare end phase). The blank ionogram at $1345 \mathrm{hr}$ demonstrates the absorption effects at lower altitudes due to the flare action. This absorption effect is manifested in the ionogram of $1400 \mathrm{hr}$ also although the effect is reduced. On the other hand, the $1430 \mathrm{hr}$ ionogram shows the presence of sporadic $\mathrm{E}$ as well as the F layer trace and these features are similar to those seen in the ionogram of $1330 \mathrm{hr}$ before the flare onset. Moreover, the ionograms indicate a weakening in sporadic E in the interval between 1409 and $1430 \mathrm{hr}$ showing that that the electric field has reduced during this period and this results in the fall in power and $\mathrm{H}$ variations seen during this time. This reduction in electric field is probably due to the disturbance effects. Thus the signatures seen in different parameters during the two time slots are clearly different indicating that the first one corresponds to flare effects and the second one to disturbance effects. Beyond $1500 \mathrm{hr}$ the signal increases considerably in the 99-104 km region. The decrease of signal from the onset phase to the peak phase as well as the increase in signal after the peak phase is demonstrated in this case also.

The time variations of the mean Doppler frequency $\left(\overline{f_{D}}\right)$ values for 25 March 1991 event at 99, 101, 104 and $107 \mathrm{~km}$ are shown in Fig. 7. NS indicates no signal condition in top panel. In the other panels, a break in $\overline{f_{D}}$ plots around 1343 $\mathrm{hr}$, indicates the radar signal disappearance (signal strength falling to noise level) close to flare peak phase and the consequent non-availability of $\overline{f_{D}}$ values. The pattern of variation of $\overline{f_{D}}$ on this day deviates from the quiet day pattern of a gradual increase in the morning, a broad peak around noon and a gradual decrease to very low values in the late afternoon hours. Sample time variations of $\Delta \mathrm{H}$ and $\overline{f_{D}}$ for a quiet day are shown in Fig. 8. The values of both the parameters do not show the large amplitude fluctuations seen on 25 March 1991. This different behaviour on 25 March 1991 is due to disturbance associated westward electric fields manifesting in $\overline{f_{D}}$ values. Fluctuating components in $\overline{f_{D}}$ values are also more dominant over the background level as it is a disturbed day (Viswanathan, 1986).

The radar signal is present during the time of the flare (except close to the peak phase) at the altitudes of 99, 101 and $104 \mathrm{~km}$. At $99 \mathrm{~km}$, the $\overline{f_{D}}$ value decreases from $-38 \mathrm{~Hz}$ just prior to the onset of the flare to $-36 \mathrm{~Hz}$ at $1333 \mathrm{hr}$. Be- 


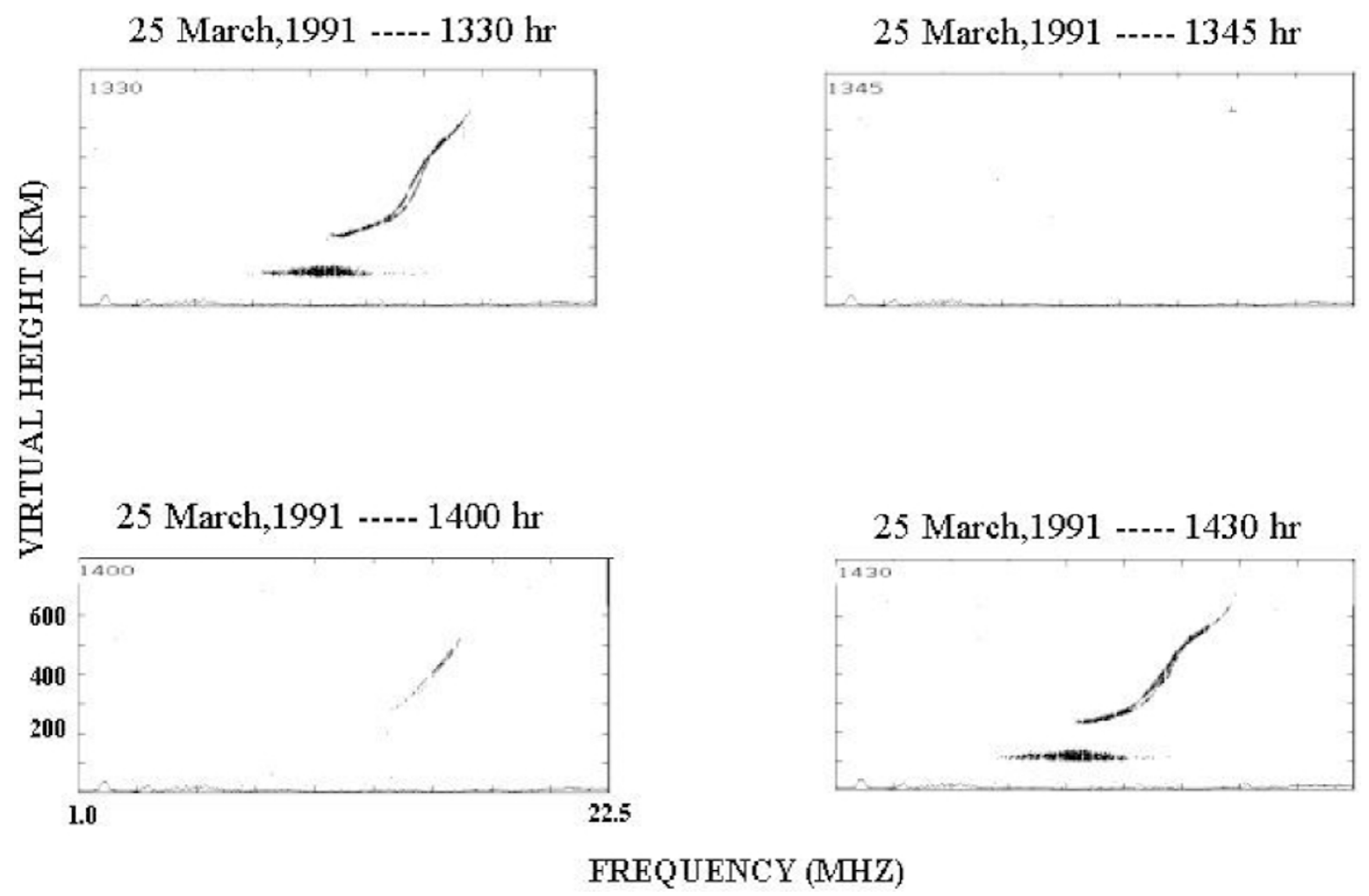

Fig. 6. Ionograms corresponding to $1330 \mathrm{hr}$ (before flare onset), $1345 \mathrm{hr}$ (close to flare peak phase), $1400 \mathrm{hr}$ (close to end phase) and $1430 \mathrm{hr}$ (after flare end phase).

25 MAR. 1991 (AD $=1311$

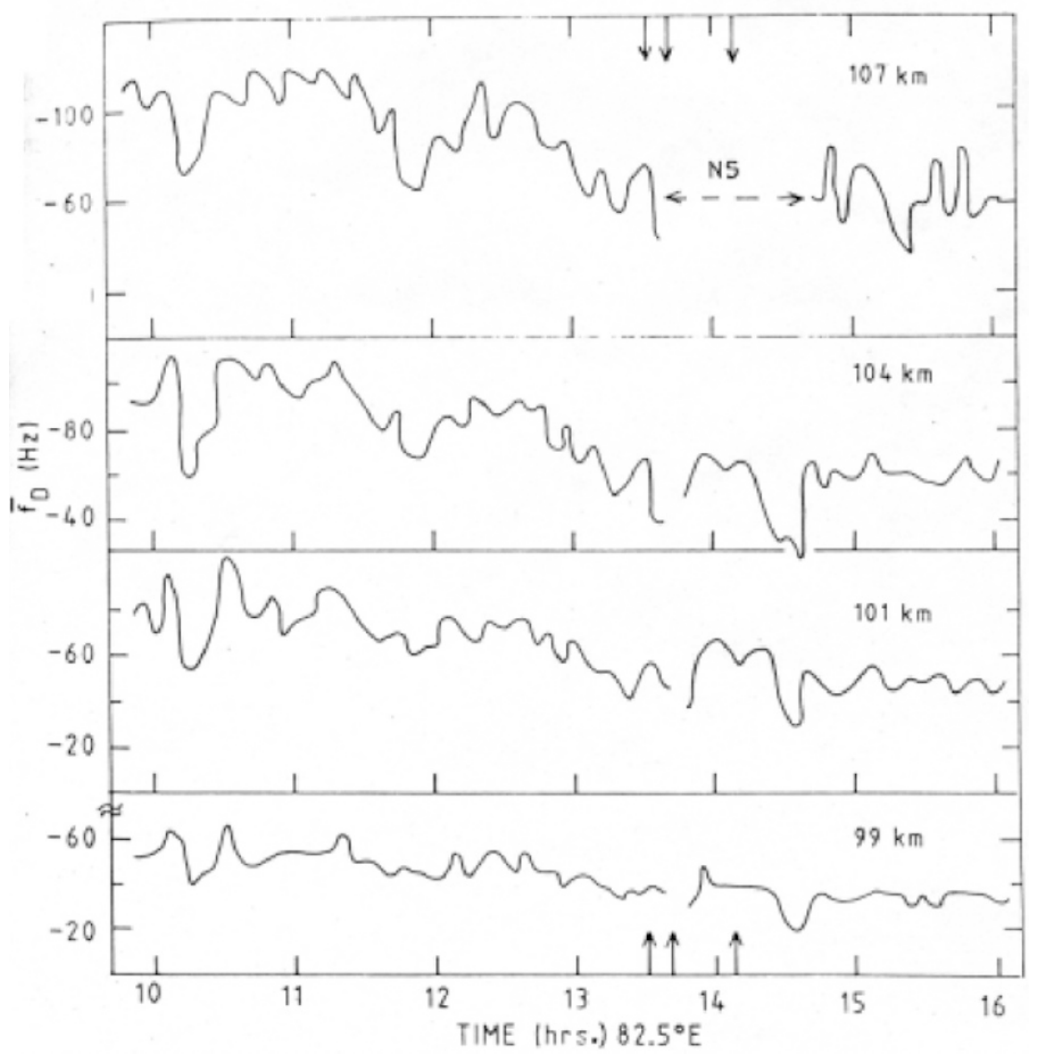

Fig. 7. The variation of mean Doppler frequency $\left(\overline{f_{D}}\right)$ on 25 Mar 1991 corresponding to the altitude range of $99-107 \mathrm{~km}$. 

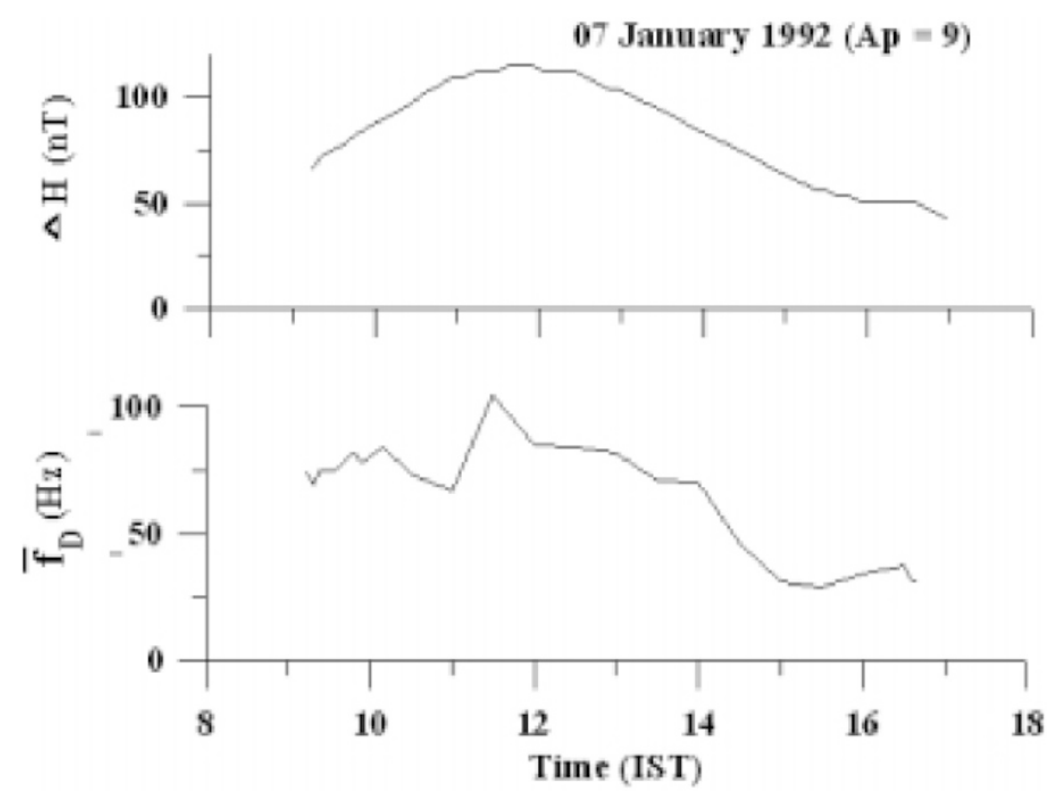

Fig. 8. The daytime variations of $\Delta \mathrm{H}$ and $\overline{f_{D}}$ on the quiet day of 07 January 1992.

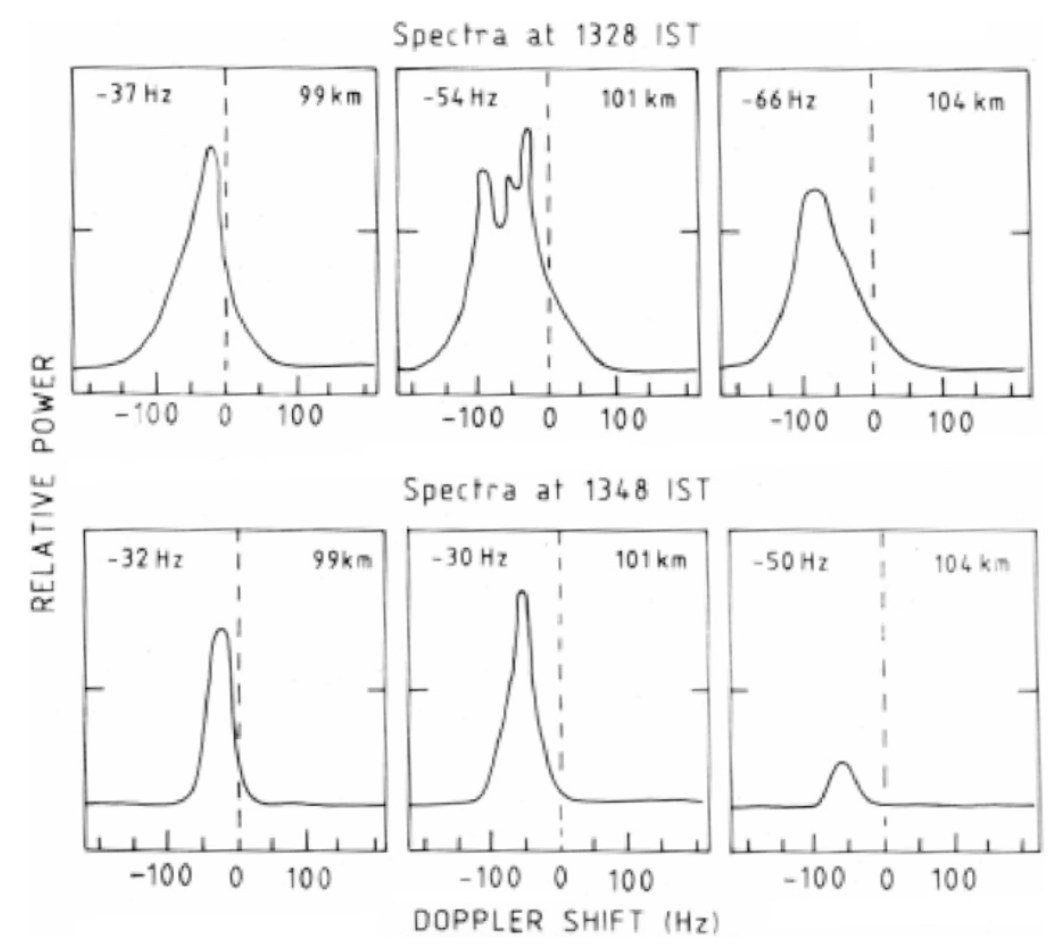

Fig. 9. Sample VHF radar Doppler spectra at three altitudes (99, 101 and $104 \mathrm{~km})$ on 25 March 1991.

yond $1333 \mathrm{hr}$ no signal condition prevails up to $1348 \mathrm{hr}$, as the radar sensitivity is not sufficient to detect the backscattered echoes during this period. At $1348 \mathrm{hr}$ when the signal reappears the $\overline{f_{D}}$ value is $\sim-30 \mathrm{~Hz}$. Thereafter, the $\overline{f_{D}}$ values recover gradually to $\sim-40 \mathrm{~Hz}$ by $1409 \mathrm{hr}$ (end phase of the flare). At the altitude of $101 \mathrm{~km}, \overline{f_{D}}$ decreases from $-54 \mathrm{~Hz}$ (prior to the onset of the flare) to $-46 \mathrm{~Hz}$ at 1338 hr. The signal reappears after disappearance with an $\overline{f_{D}}$ value of $-38 \mathrm{~Hz}$. Beyond $1348 \mathrm{hr}$ the $\overline{f_{D}}$ values recover to $\sim-60 \mathrm{~Hz}$ by $1409 \mathrm{hr}$. Similar pattern is seen for $104 \mathrm{~km}$ also. For the altitude of $107 \mathrm{~km}$, the radar signal is absent during the peak phase of the flare event and beyond (up to
$1500 \mathrm{hr}$ ). The sharp fall in $\overline{f_{D}}$ values close to the peak phase of this X-ray flare event is shown in Fig. 7. During X-ray flare events, the electron density increases and maximises at the peak phase of the flare, and the effects on $\overline{f_{D}}$ and backscattered power values from the electrojet, also maximise corresponding to the peak phase. Sample Doppler spectra obtained for 99,101 and $104 \mathrm{~km}$ prior to the start (top three panels) and close to the peak phase (bottom three panels) of this event are shown in Fig. 9. The spectra clearly reveal the reduction in the $\overline{f_{D}}$ values around the flare peak phase.

The electron drift velocity, Vey as given by (Balsley, 


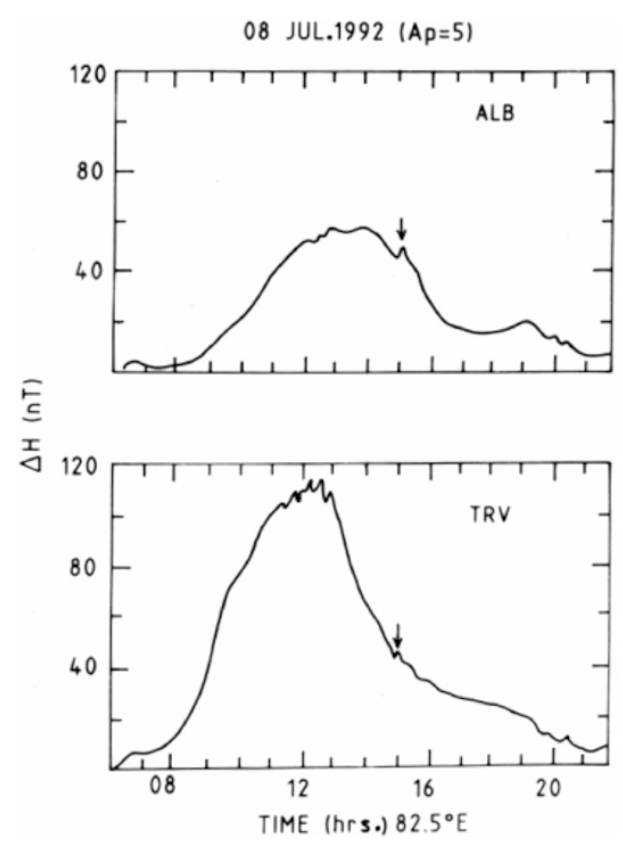

Fig. 10. Daytime variations of $\Delta H$ at TRV and ALB on 08 July 1992. Inverted arrows indicate the peak phase of the $\mathrm{X}$-ray flare event.

1973; Reddy et al., 1987) is

$$
V_{\text {ey }}=\overline{f_{D}} \lambda(1+\alpha)
$$

where $\lambda$ is the radar wavelength and $\alpha$ is the collision frequency parameter given by

$$
\begin{gathered}
\alpha=v_{i} v_{e} / \Omega_{i} \Omega_{e} . \\
E_{z}=V_{\text {ey }} B
\end{gathered}
$$

where $B$ is the earth's magnetic field; $v_{i}$, and $v_{e}$ are the collision frequencies of ions and electrons respectively; $\Omega_{i}$ and $\Omega_{e}$ are the gyro frequencies of ions and electrons respectively.

Hence, $\overline{f_{D}}$ reduction implies a fall in $V_{\text {ey }}$, which in turn causes a fall in $E_{z}$ as it $\left(E_{z}\right)$ is directly proportional to $V_{\mathrm{ey}}$.

\subsection{July 1992 event}

08 July 1992 is again a magnetically quiet day as indicated by the Ap value of 5. The information relating to the flare event, which occurred on this day, is given in Table 1. The flare begins at $1512 \mathrm{hr}$, peaks at $1520 \mathrm{hr}$ and ends at $1556 \mathrm{hr}$.

The variations of $\Delta \mathrm{H}$ values at TRV and ALB during daytime are shown in Fig. 10. The solar X-ray flare related excursion in $\Delta \mathrm{H}$ is indicated in both panels by a downward arrow. The $\Delta \mathrm{H}$ values increase from morning, attain a maximum value of $110 \mathrm{nT}$ at $1245 \mathrm{hr}$. From $\sim 1300 \mathrm{hr}$ the values start decreasing rather sharply. After the flare related increase, $\Delta \mathrm{H}$ values again decrease, and attain very low values in the evening hours. The $\Delta \mathrm{H}$ values at ALB also increase from morning and attain a peak value of $\sim 60 \mathrm{nT}$ by $1245 \mathrm{hr}$. The flare related increase in $\Delta \mathrm{H}$ can be clearly seen in the case of Alibag also. Moreover the SFE (H) amplitude is larger at ALB than at TRV, which is in contrast to what has been seen for the other events discussed.

The time variations of the backscattered power (during daytime) for the altitudes of 94, 96, 99, 101, 104 and 107 km for 08 July 1992, are shown in Fig. 11. The gap in the power plots at different altitudes $\sim 0945 \mathrm{hr}$ indicates non-availability of data. The radar signal is absent during flare time and later, at the altitudes of 94 and $107 \mathrm{~km}$. However, it can be seen that the signal reappears in the late afternoon hours $(\sim 1730 \mathrm{hr})$ at $107 \mathrm{~km}$. In the figure, the backscattered power gradually increases in the morning, attains maximum close to noon and then decreases. The power falls off rapidly to noise level during the peak phase of the flare. After the peak phase the power again increases before decreasing due to fall in conductivity in the evening hours.

The variation of $\overline{f_{D}}$ with time in the altitude region of 94-107 km for 08 July 1992 event, is illustrated in Fig. 12. ND indicates no data. The small break in the $\overline{f_{D}}$ plots close to $1520 \mathrm{hr}$ corresponds to absence of signal around the flare peak phase (signal falling to noise level). Another interesting aspect for this event is the reversal of $\overline{f_{D}}$ to positive values indicating westward electric field in the altitude range of 94 to $104 \mathrm{~km}$, whereas the $\overline{f_{D}}$ values from morning are negative indicating the presence of eastward electric field. The positive $\overline{f_{D}}$ values persist for a longer duration of 2-3 hrs, in contrast to the transient SFE phenomenon. The Xray flare event is riding over an already reversed electrojet condition as indicated by the radar observations. The presence of westward electric field at Trivandrum during the $\mathrm{X}$-ray flare event, contributes to the $\Delta \mathrm{H}$ values there, and hence the observed SFE $(\mathrm{H})$ amplitude is smaller than that at ALB. The reversed electrojet effects are not seen at ALB, which is a station outside the electrojet belt region. The observation of reversed Doppler values is confined to altitudes below $107 \mathrm{~km}$. This is a feature observed during counter electrojet events, very often. The observation of westward electric field using radar data, while the $\Delta \mathrm{H}$ values are positive, have been reported earlier for many partial CEJ events. The new observation for this partial CEJ event is that the westward electric field persists for a longer duration of 2-3 hours unlike the usual brief presence of the reversed field (during CEJ events).

\subsection{X-ray flare events of lower rank}

A number of lesser rank X-ray flare events ( $\mathrm{M}$ and $\mathrm{C}$ rank) have been examined to study the EEJ response to them. The peak burst intensity $I_{B}$, for $\mathrm{M}$ rank flares is between $10^{-5}$ and $10^{-4} \mathrm{Wm}^{-2}$, while for $\mathrm{C}$ rank flares it is between $10^{-6}$ and $10^{-5} \mathrm{Wm}^{-2}$.

From an examination of the temporal variations of the backscatter radar signal power and $\overline{f_{D}}$ values for lesser rank flares, no clearly identifiable behaviour could be delineated. No significant reduction in backscattered power is observed around the peak phases of these types of flares, unlike in the case of strong flares.

\subsection{Estimation of $\int \sigma_{2} d s / \int \sigma_{1} d s$ for X-ray flare times} vis-à-vis normal times

The vertical polarization electric field $\left(E_{z}\right)$ in the EEJ is given (Richmond, 1973a) by the relation

$$
E_{z}=\left[\int \sigma_{2} d s / \int \sigma_{1} d s\right] E_{y}
$$

$E_{y}$ is the global curl free E-W electric field, $\sigma_{1}$ is the Pedersen conductivity and $\sigma_{2}$ the Hall conductivity, ds is the 


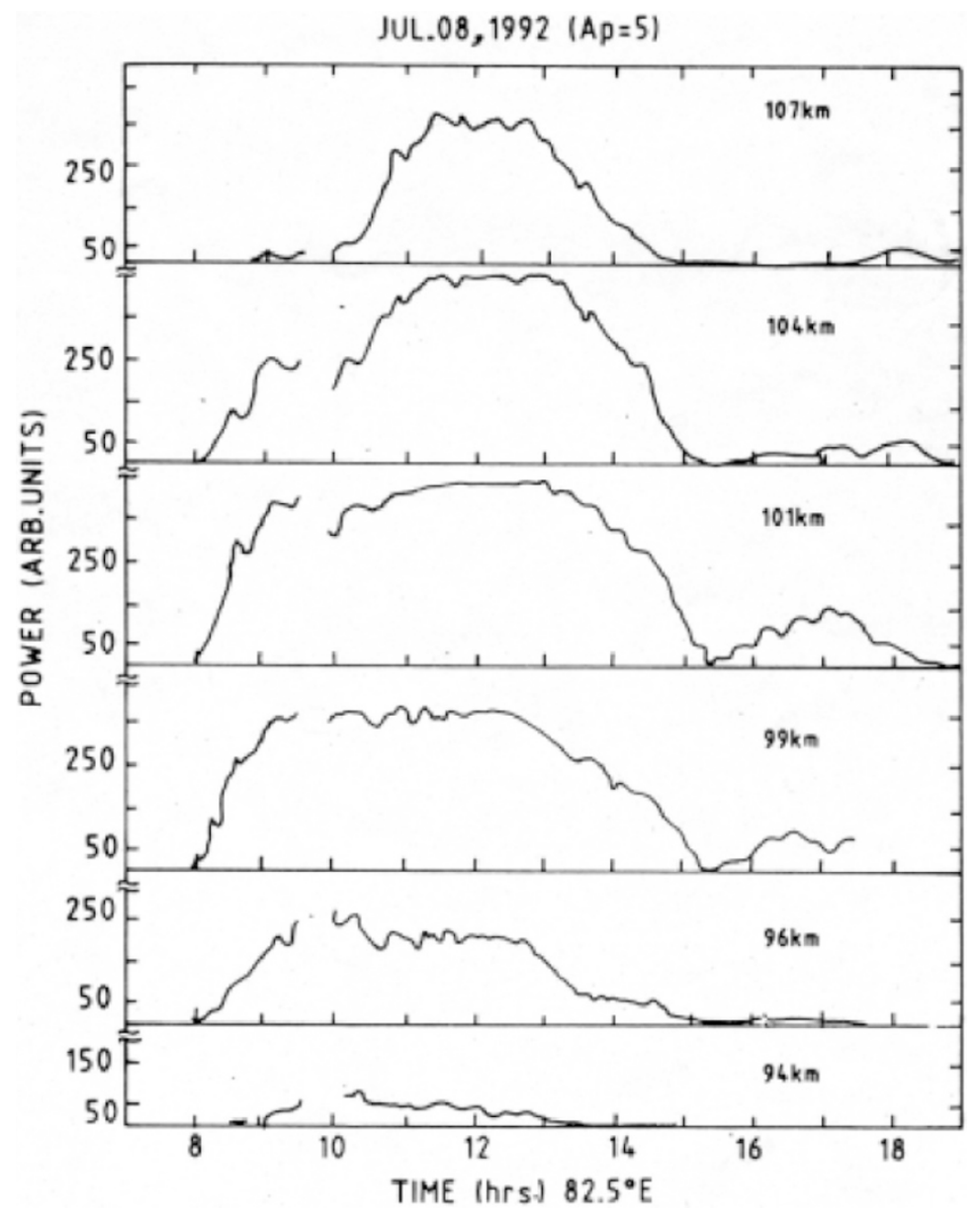

Fig. 11. Daytime variations of backscattered power at six altitudes in the range of 94-107 km on 08 July 1992.

elemental length of the geomagnetic fileld line along which integration is carried out from an altitude in the dynamo region to an altitude, where the conductivities become negligibly small. The conductivities $\sigma_{1}$ and $\sigma_{2}$ depend on the electron density $\left(N_{e}\right)$, the collision and gyro frequencies of ions and electrons. For the computation of $\sigma_{1}$ and $\sigma_{2}$ values corresponding to non-flare times, $N_{e}$ profiles at Trivandrum, obtained from rocket measurements (Subbaraya et al., 1983) for the altitude region $60-150 \mathrm{~km}$, have been used. The $\sigma_{1}$ and $\sigma_{2}$ values have also been computed for strong flare conditions. For this purpose $N_{e}$ profiles from 60 to around $90 \mathrm{~km}$ (D region) have been obtained from Mitra and Deshpande (1972). For the altitudes from around $90 \mathrm{~km}$ the profiles have been obtained based on the fact that the $N_{e}$ enhancement in the E region for strong flares is $\sim 100 \%$ (Mitra and Subrahmanyam, 1972). The $N_{e}$ profiles used during normal and strong flare times are shown in Fig. 13. The significant increase in the $N_{e}$ values in the $\mathrm{D}$ region during strong flares is seen in the figure. During non-flare times, in the $60-90 \mathrm{~km}$ region, the $N_{e}$ values are quite small compared to the values at higher altitudes with the value at $80 \mathrm{~km}$ being of the order of $10^{8} / \mathrm{m}^{3}$. During flare times the $N_{e}$ values in this region increase to as much as $10^{10} / \mathrm{m}^{3}$ at $80 \mathrm{~km}$. The collision frequency values for the conductivity computations have been obtained using Banks and Kockarts (1973) model. The computed value of $\sigma_{1}$ at $100 \mathrm{~km}$ is $1.1 \times 10^{-5} \mathrm{mho} / \mathrm{m}$ during normal times without flare), while that of $\sigma_{2}$ is $2.5 \times 10^{-4} \mathrm{mho} / \mathrm{m}$. The corresponding flare time values are $2.2 \times 10^{-5} \mathrm{mho} / \mathrm{m}$ and $5 \times 10^{-4} \mathrm{mho} / \mathrm{m}$ respectively (at $100 \mathrm{~km}$ ). This increase is a result of the $N_{e}$ enhancement particularly in the E region during flares. The $\sigma_{1}$ and $\sigma_{2}$ profiles peak at different altitudes and have different shapes. Therefore when integrated conductivities are computed over the altitude region of 70 $150 \mathrm{~km}$, the values obtained will depend on the relative $N_{e}$ enhancements at different altitudes.

The factor $\int \sigma_{2} d s / \int \sigma_{1} d s$ is estimated both for strong flare (enhanced $N_{e}$ ) and non-flare (normal $N_{e}$ ) times. Figure 14 shows the altitude profiles of the factor for non-flare and strong flare times. It is seen that the effect of the enhanced $N_{e}$ values during strong flares is to reduce the value of the factor quite substantially. The peak value of the factor decreases to around 15 during flare times from the value of 30 during non-flare times. The reduction is seen to be more at the lower altitudes. Since $E_{z}$ depends on the factor $\int \sigma_{2} d s / \int \sigma_{1} d s$, and $E_{y}$ it can be seen that the decrease in the factor gives rise to a reduced $E_{z}$ for a given $E_{y}$ magnitude. It is to be mentioned that the reduction in the above factor depends on the magnitude of increase in $N_{e}$ values at different altitudes and also on the shape of the $N_{e}$ profile from $\mathrm{D}$ region altitudes onwards, in addition to the time of occurrence of the flare. 


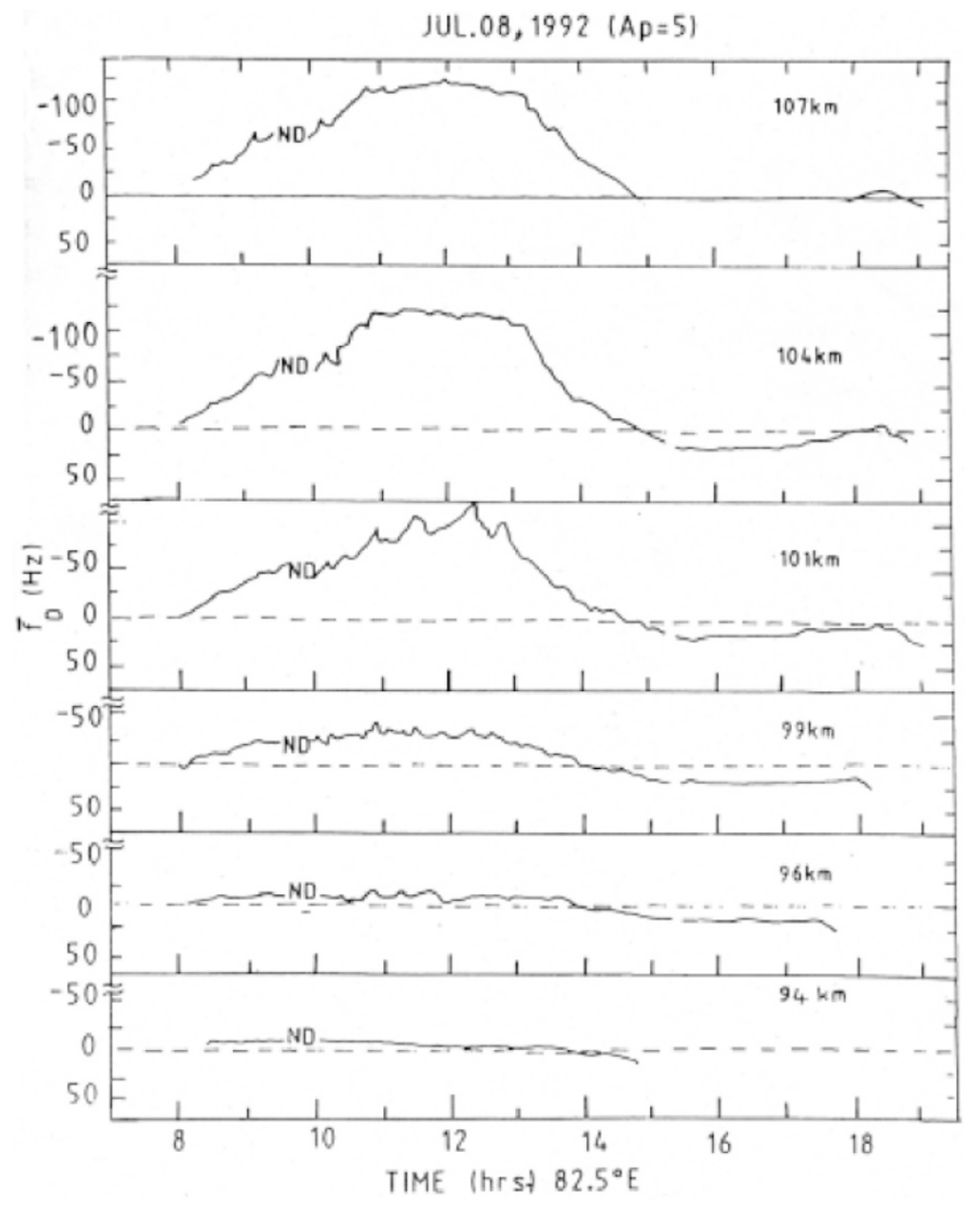

Fig. 12. Same as Fig. 8, for $\overline{f_{D}}$ variations.

\section{Discussion}

Ionospheric effects of solar flares have been studied in the past using Thomson scatter measurements (Thome and Wagner, 1971). The studies brought out strong electron density enhancement in the E region of the order of $100 \%$ and moderate enhancement in the $\mathrm{F}$ region. In the present study, coherent VHF backscatter radar observations at Trivandrum in association with ground based magnetic field variations ( $\Delta H$ values) at and off EEJ latitudes have been used to study the behaviour of EEJ electric fields and currents during solar X-ray flares of different ranks.

For a number of events studied, it is seen that the SFE $(\mathrm{H})$ amplitude decreases from TRV to ALB. It is seen that the ratio of SFE $(\mathrm{H})$ at TRV to that at ALB for daytime conditions is in the range of 1.8-2.6 in the absence of CEJ effects. Further, it is also observed that the ratio of $\Delta \mathrm{H}$ at TRV to that at ALB for non-flare times is also in the same range. The $\Delta H$ variations depend on the currents in the EEJ itself in addition to currents (internal) induced by the jet (Sampath and Sastry, 1979). The current density $\mathrm{j}$ at any altitude in the EEJ region depends on the conductivity and the electric field. Assuming the global electric field $E_{y}$ to be reasonably constant at the two locations of TRV and ALB, the difference in $\Delta \mathrm{H}$ values at the two latitudes may be attributed to the difference in conductivities between the two locations. Thus the reduction in SFE $(\mathrm{H})$ amplitude from
TRV to ALB can be due to the reduction in conductivities from equator to low latitudes.

The SFE (H) at TRV is less than that at ALB for the event of 08 July 1992, which is in contrast to the observations on other days. This reduction in amplitude is due to the presence of a counter electrojet (CEJ) prior to, during and after the flare event. The X-ray flare event causes increase in $\mathrm{H}$ component while the CEJ effect tends to reduce it. As ALB lies outside the electrojet belt, the CEJ effects are not significant there. Hence the SFE $(\mathrm{H})$ amplitude is unaffected, but at TRV the combined effects of SFE and CEJ result in the SFE $(\mathrm{H})$ amplitude getting reduced. This CEJ event is a partial one wherein the $\Delta \mathrm{H}_{\mathrm{TRV}}$ values do not show even a depression. The $\Delta \mathrm{H}_{\mathrm{TRV}}-\Delta \mathrm{H}_{\mathrm{ALB}}$, values are negative from $\sim 1440 \mathrm{hr}$ to $\sim 1535 \mathrm{hr}$. with the maximum depression being observed at $\sim 1515 \mathrm{hr}$ of about -8 nT. Another interesting aspect for this event is that, the radar observations show CEJ effects (reversed Doppler and westward electric field presence) as has been discussed previously. $\Delta \mathrm{H}_{\mathrm{TRV}}-\Delta \mathrm{H}_{\mathrm{ALB}}$, values are negative from 1440 hr to 1535 hr. Similarly, on 24 December 1991 also a partial CEJ event is in progress when the solar flare event occurs. The presence of a westward electric field in the EEJ region, as observed using radar, while the magnetic field does not show a depression below nighttime level has been reported by Reddy et al. (1980) and Viswanathan (1986). They have 


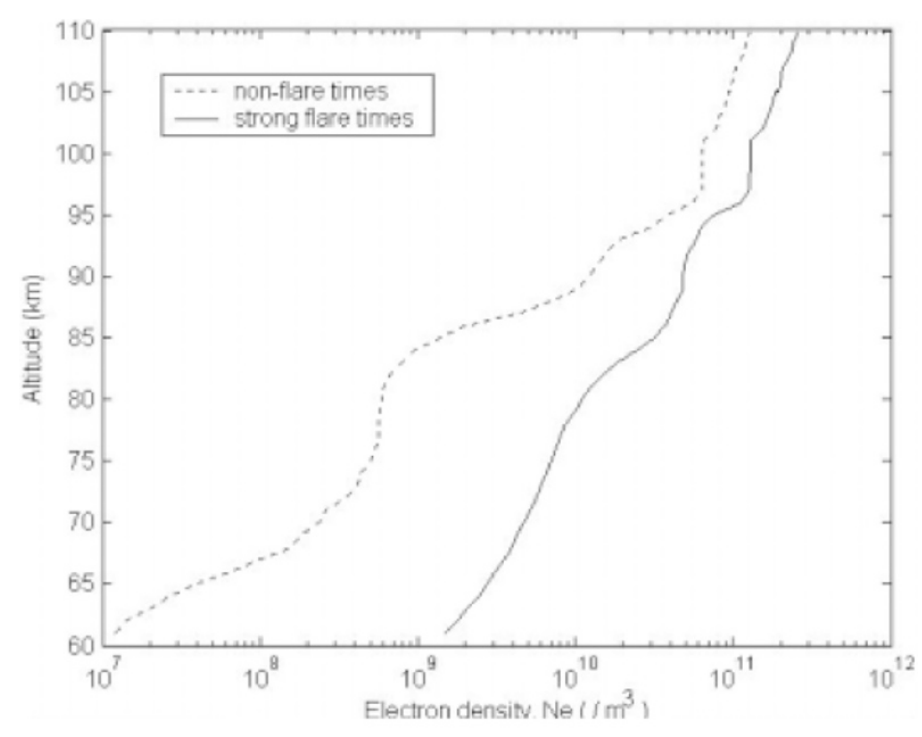

Fig. 13. Electron density profiles for the altitude range of $60-150 \mathrm{~km}$ during non-flare and X-ray flare times.

presented in detail the implications of such observations in relation to the lunar phase. Several studies on solar flare events occurring in the presence of a counter electrojet have been reported earlier (Srivastava, 1974; Sastri, 1975; Rastogi et al., 1975; Rangarajan and Rastogi, 1981; Rastogi et al., 1999). These studies have shown that SFE (H) amplitude is lower at equator and higher for stations outside the jet due to the counter electojet related decreasing effect on $\Delta \mathrm{H}$. The characteristics of the electrojet response, to solar flares, under conditions of counter electrojet, have been described by Rastogi et al. (1999). They have also confirmed the existence of zonal and meridional components of the ionospheric currents over the eqatorial latitudes, which in combination with $S_{q}$ currents produce complex effects (as seen during flares occurring at the time of partial CEJ events).

In the present study, it has been consistently seen that the backscattered power gets reduced substantially (by more than 90\%) at the peak phase of X-rank flare events with respect to the pre-flare level. No such reduction could be seen in radar observations of lesser rank flares. There is a significant enhancement in $N_{e}$ in the $\mathrm{D}$ and $\mathrm{E}$ regions of the ionosphere during strong flares. The increase is more in the $\mathrm{D}$ region than in the $\mathrm{E}$ region. The enhanced $N_{e}$ in the $\mathrm{E}$ region is probably producing a weakening of the electron density gradients. According to the gradient drift instability mechanism, which generates the type II irregularities, the condition for the growth of type II irregularities is that the electron density gradient and electric field have to be in the same direction (Fejer and Kelly, 1980). The scattering cross-section of type II irregularities is also approximately proportional to the square of the electron drift velocity and the electron density gradient (Farley and Balsley, 1973). When either of these two parameters decreases the type II irregularity echoes get weaker. Hence the backscattered power from the type II irregularities is dependent on $\nabla \mathrm{N}$ and $V_{\text {ey }}$ and it will show a reduction when $\nabla \mathrm{N}$ and/or $V_{\text {ey }}$ decreases. It is seen from the radar observations on 25 March 1991 that there is a fall in $\overline{f_{D}}$ close to the peak phase

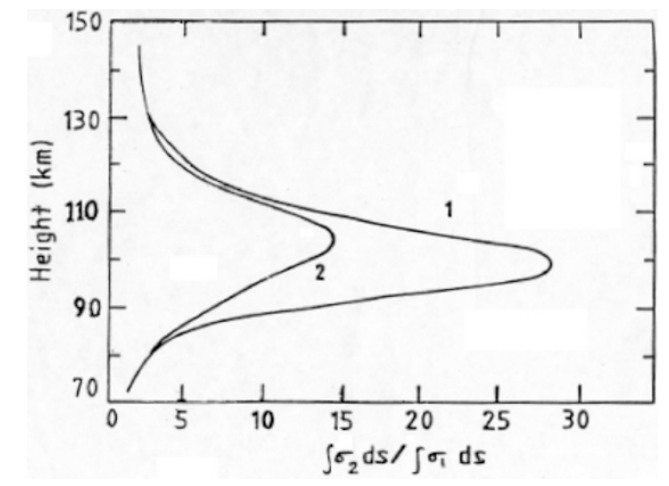

Fig. 14. Altitude profiles of $\int \sigma_{2} d s / \int \sigma_{1} d s$ for no flare (1) and strong flare (2) conditions.

of the flare by about $10-30 \mathrm{~Hz}$ with respect to the pre flare level. A reduction in $\overline{f_{D}}$ implies a reduction in $V_{\text {ey. }}$. This $V_{\text {ey }}$ reduction, either in combination with a reduced $\nabla \mathrm{N}$ or on its own produces the observed reduction in backscattered power, around the flare peak phase. For weak flare events, $N_{e}$ increase is not substantial and hence reduction in $\nabla \mathrm{N}$ and or $V_{\text {ey }}$ is not noticeable.

As shown previously, during a strong flare event, the value of the factor $\int \sigma_{2} d s / \int \sigma_{1} d s$ reduces depending on the degree of $N_{e}$ enhancement. This reduction in the factor implies a reduction in $E_{z}$, for a given $E_{y}$. This reduction in $E_{z}$ is actually manifested in the radar observed Doppler frequency variations close to the peak phase of strong flares. For lesser rank flares the $N_{e}$ enhancement is insignificant and reduction is not seen in $\int \sigma_{2} d s / \int \sigma_{1} d s$ and hence in $E_{z}$.

It is seen that $\Delta \mathrm{H}$ shows significant increase during strong flares. Both conductivity and electric field contribute to the observed $\Delta \mathrm{H}$. To exactly explain the increase in $\Delta \mathrm{H}$, information about the conductivity as well as the electric field is required. In the present study, it is not possible to infer the changes, if any, in $E_{y}$ during strong flares. To deduce the changes, if any, in $E_{y}$ during strong flares, more studies 
using radar observations with much greater time resolution are to be carried out both for electrojet and off electrojet stations. Such studies (during strong flare times) will bring out the relative contributions of $E_{y}$ and $E_{z}$ to the total current density and also to $\Delta \mathrm{H}$ as the $E_{z}$ contribution is confined only to electrojet latitudes. Some workers have suggested the possibility that during flare events the ionospheric current system is lower than the usual $S_{q}$ current system (Oshio et al., 1967). The real location of the flare time current system can be identified only using data from a network of stations (both equatorial and off equatorial) as mentioned above. Nevertheless, the present study focuses attention on some important changes occurring in the ionospheric current system during strong flares.

\section{References}

Balsley, B. B., Electric fields in the equatorial ionosphere: A review of techniques and measurements, J. Atmos. Terr. Phys., 35, 1035-1044, 1973.

Banks, P. M. and G. Kockarts, Aeronomy, Part A., Academic press, New York, 1973.

Chapman, S., Regular motions in the ionosphere: Electric and magnetic relationships, Bull. Amer. Meteorol. Soc., 42, 85, 1961.

Donelly, R. F., An analysis of sudden ionospheric disturbances associated with the proton flare of 1522 UT, Aug. 28, 1966, ESSA Tech. Rep. ERL 92-SDL6, U. S. Government printing office, Washington, D. C., 1968.

Farley, D. T. and B. B. Balsley, Instabilities in the equatorial electrojet, $J$. Geophys. Res., 78, 227, 1973.

Fejer, B. G. and M. C. Kelly, Ionospheric irregularities, Rev. Geophys. And Space Phys., 18, 401, 1980.

Mitra, A. P. and S. D. Despande, Flaretime models of ionisation profiles in the D region, Space Research XII, Akademic, Verlag, Berlin, 1291, 1972.

Mitra, A. P. and C. V. Subrahmanyam, Sudden ionospheric disturbances, Ind. J. Rad. Space Phys., 1, 93, 1972.

Oshio, M., N. Fukushima, and T. Nagata, Solar flare effects on geomagnetic field, Rep. Ionos. Space Res. Japan, 21, 77-114, 1967.

Rangarajan, G. K. and R. G. Rastogi, Solar flare effect in equatorial magnetic field during morning counter electrojet, Ind. J. Rad. Space Phys., 10, 190-192, 1981.

Rastogi, R. G., Solar flare effects on zonal and meridional currents at the equatorial electrojet station, Annamalainagar, J. Atmos. Terr. Phys., 58, 1413-1420, 1996.
Rastogi, R. G., M. R. Deshpande, and N. S. Sastri, Solar flare effect in equatorial counter electrojet current, Nature (London), 258, 218-219, 1975.

Rastogi, R. G., D. R. K. Rao, S. Alex, B. M. Pathan, and T. S. Sastry, An intense SFE and SSC event in geomagnetic H, Y and Z fields at the Indian Observatories, Ann. Geophys., 15, 1301-1308, 1997.

Rastogi, R. G., B. M. Pathan, D. R. K. Rao, T. S. Sastry, and J. H. Sastri, Solar flare effects on the geomagnetic elements during normal and counter electrojet periods, Earth Planets Space, 51, 947-957, 1999.

Reddy, C. A., V. V. Somayajulu, and K. S. Viswanathan, The lunar phase and the equatorial electrojet, Low latitude aeronomical processes, COSPAR Symp. Ser., edited by A. P. Mitra, Pergamon, New York, 29, 1980.

Reddy, C. A., B. T. Vikramkumar, and K. S. Viswanathan, Electric fields and currents in the equatorial electrojet deduced from VHF radar observations-I. A method of estimating electric fields, J. Atmos. Terr. Phys., 49, 183, 1987.

Richmond, A. D., Equatorial electrojet. I. Development of a model including winds and instabilities, J. Atmos. Terr. Phys., 35, 1083-1103, 1973a.

Richmond, A. D., Equatorial electrojet. II. Use of the model to study the equatorial ionosphere, J. Atmos. Terr. Phys., 35, 1105-1118, 1973 b.

Sampath, S. and T. S. G. Sastry, Results from in situ measurements of ionospheric currents in the equatorial region, J. Geomag. Geoelectr., $\mathbf{3 1}$ 373, 1979.

Sastri, J. H., The geomagnetic solar flare effect of 6 July 1968 and its implications, Ann. Geophys., 31, 481, 1975.

Sato, T., The response of the lower ionosphere to the great solar flare of August 7, 1972, J. Geomag. Geoelectr., 27, 383, 1975.

Srivastava, B. J., The geomagnetic solar flare effect of 03 May 1973 at Indian stations and its dependence on the counter electrojet, J. Atmos. Terr. Phys., 36, 1571, 1974.

Subbaraya, B. H., S. Prakash, and S. P. Gupta, Electron densities in the equatorial lower ionosphere from the Langmuir probe experiments conducted at Thumba during the years 1966-1978, ISRO-PRL Special Report, ISRO-PRL-SR-15-83, 1983.

Thome, G. D. and L. S. Wagner, Electron density enhancements in the E and $\mathrm{F}$ regions of the ionosphere during solar flares, J. Geophys. Res., 76 , 6883, 1971.

Van Sabben, D., Solar flare effects and simultaneous magnetic daily variation, J. Atmos. Terr. Phys., 30, 1641, 1968.

Viswanathan, K. S., Study of electrodynamics of the equatorial electrojet, Ph.D. thesis, University of Kerala, India, 1986.

Yasuhara, M. and H. Maeda, Geomagnetic Crochet of 15 November 1960, J. Atmos. Terr. Phys., 21, 289, 1961.

G. Manju (e-mail: manju_spl@vssc.org) and K. S. Viswanathan 